\title{
Social carrying capacity assessment from questionnaire and counts survey: Insights for recreational settings management in coastal areas
}

\author{
Gonson Charles ${ }^{1,2,{ }^{*}}$, Pelletier Dominique ${ }^{1}$, Alban Frederique ${ }^{3}$
}

${ }^{1}$ IFREMER, UR Lagons, Ecosystèmes et Aquaculture Durable en Nouvelle Calédonie (LEAD-NC), 101 promenade Roger Laroque, BP 2059, 98846 Noumea Cedex, New Caledonia

${ }^{2}$ IRD, UMR ENTROPIE, Université de Perpignan Via Domitia, 52 Avenue Paul Alduy, Perpignan, 66860 Cedex 9, France

${ }^{3}$ Univ Brest, Ifremer, CNRS, UMR 6308, AMURE, IUEM, 29280 Plouzane, France

* Corresponding author : Charles Gonson, email address : charles.gonson@hotmail.fr

\begin{abstract}
:
Because of demographic and tourism increase, coastal areas are facing higher numbers of recreational users. Together with other factors (environmental quality, protection status), the level of use affects the spatial distribution of users. This level also affects the quality of user experience, because beyond a certain level, the number of users results in decreased user satisfaction; this is the social carrying capacity (SCC), which depends on user and site characteristics. This study assessed the SCC in a popular coastal area and examined how it influences the spatial distribution of users. Boat and visitor counts as well as data from a questionnaire-based survey were analyzed to assess i) crowding perception, ii) factors affecting the disturbance associated with use level, and iii) user's coping strategies when managing high use levels. The results demonstrated that crowding perception and disturbances associated with use level depend on-site characteristics, use level, and user characteristics. Boat type was the main factor affecting user's coping strategy. SCC significantly differed between sites and according to the use level anticipated by users. The SCC was fulfilled at every site within the marine protected areas, except for the sites experiencing the lowest use level. This study provides novel and valuable information for the field of recreational use management, when attempting to achieve either sustainable use goals through SCC assessment or biodiversity conservation goals through the effect of SCC on the spatial distribution of pressures related to recreational uses.
\end{abstract}

\section{Highlights}

- Recreational users count and survey data were collected on same sites. Recreational users often under estimate the number of present visitors and boats. Number of boats and visitors is the main disturbance due to use level. Every MPA sites reached the social carrying capacity. Facing high use level, the coping strategy of users depends on boat type.

Keywords: Marine protected areas, Recreational users, Social carrying, capacity, Coping strategy, New Caledonia 


\section{Introduction}

28 Demography and tourism are developing worldwide (Duedall and Maul, 2005), especially in 29 coastal areas, where more users concentrate within recreational settings (Orams, 1999), 30 leading to higher pressures on the natural environment. Marine protected areas (MPAs) aim 31 at limiting these pressures and associated impacts (Wood et al., 2008, De Santo, 2013). 32 Although MPAs have become more numerous and larger between 2006 and 2016, MPAs most often do not regulate the number of entrances, whether beach visitors or boaters

34 (Shivlani and Suman, 2000; Smallwood et al., 2012a).

35 How recreational users are distributed in coastal areas depends on the experience sought 36 for by users and the characteristics offered by existing recreational settings (Clark and 37 Stankey, 1979). Among these, the anticipated or experienced number of boats or visitors 38 was hypothesized to largely influence the selection by any user of the recreational setting 39 (Bujosa et al., 2010). Under this assumption, changes in user numbers will alter their spatial 40 distribution, practices (i.e. the manner in which they perform activities), and resulting 41 pressures. A better understanding of these relationships, that is, between the number of 42 users and their spatial distribution, is important for environmental managers to account for 43 and anticipate subsequent anthropogenic pressures, particularly in MPAs.

44 Wagar (1964) defined the carrying capacity (CC) of a natural area for recreation as follows, 45 "a quantitative limit beyond which undesirable consequences may occur." He referred to 46 two dimensions of $\mathrm{CC}$ linked to the impact of touristic and recreational activities in wild 47 lands: i) impact on ecological state (i.e., resource degradation) and ii) impact on social 48 conditions (i.e., a decrease in visit quality). Vourc'h (1999) clarified impact on social 49 conditions as "the touristic level that a natural or cultural site can accept without that it 50 decreases its quality, the visitation quality of visitors or lead to visitors' rejection from local 51 population." Vourc'h (1999) definition raises the issue of the social acceptance of tourism. 52 With these two dimensions, an assessment of CC (Saveriades, 2000) might be difficult 53 because the use level associated with the decrease in user satisfaction might differ from that 
54 associated with ecological degradation. The present study focused on the social dimension 55 of $\mathrm{CC}$.

56 Social carrying capacity (SCC) is the level of use (often, the number of visitors) for a given 57 site, beyond which the users' quality of experience decreases or is no longer acceptable 58 (Shelby and Heberlein, 1984). The quality of recreational experience might decrease in 59 relation to the crowding effect and ecosystem degradation caused by high use level. SCC has 60 been studied in terrestrial (Shelby and Heberlein, 1986; Shelby et al., 1989; Manning et al., 61 2002; Vaske and Shelby, 2008 ; Navarro-Jurado et al., 2013, Chen and Teng, 2016) and 62 marine environments (Davis et al., 1995; Inglis et al., 1999; Needham and Szuster, 2011; 63 Szuster et al., 2011). SCC has been deemed difficult to measure because it depends on 64 individual preferences, attitudes, opinions, and experience (Lindberg et al., 1996; Navarro65 Jurado et al., 2013; Mauerhofer, 2013).

66 Shelby and Heberlein (1984) described two components of SC: an absolute "level of use" and

67 a level of use relative to the management goals of a given site (Lime and Stankey, 1971). 68 Estimating the level of use is central in SCC assessment. The number of visitors is a relevant 69 measure of the level of use, because in natural environments, crowding was negatively 70 perceived by users (Shelby et al., 1989). In addition, users' well-being might decrease when 71 disturbances occur, which is likely to be beyond an acceptable level of use. Users may then 72 implement so-called coping strategies such as moving to another site (Manning, 1999) also 73 termed displacement of users by Manning et al. (2001)]. Consequently, identifying SCC 74 requires considering the density of users and their practices.

75 How to assess SCC depends on the management goal and/or scientific question addressed 76 (Manning et Vallière, 1999; Vaske and Shelby, 2008). This study aimed to increase the 77 understanding regarding the effects of SCC on users' spatial distribution. Based on the 78 aforementioned considerations, characterizing the crowding perception of users was an 79 important first step.

80 Several examples in the literature have demonstrated that this perception depends on the 81 type of user and the recreational settings' characteristics (Kuentzel and Heberlein, 1992; 82 Vaske and Donnelly, 2002; Vaske and Shelby, 2008; Mauerhofer, 2013). Heberlein and Vaske 
83 (1977) developed an assessment method applied in greater than 180 studies (Vaske and

84 Shelby, 2008). Their method relies on asking users to evaluate the use level they are 85 experiencing during their trip. This estimate provides consistent information in relation to 86 the user's experience satisfaction and SCC assessment (Shelby et Heberlein, 1986; Kuentzel 87 et Heberlein, 1992; Navarro-Jurado et al., 2013; Brecard and De Luigi, 2016). According to 88 our review of the literature, observed counts of visitors and boats have been compared with 89 this perceived measure of use level perception (Diedrich and Tintoré, 2012; Diedrich et al., 90 2011), but this has not been the case for the estimation by users' of the numbers of visitors 91 and boats. Characterizing the relationship between observed use level, crowding perception 92 of users, and their effects on experience satisfaction increases the understanding and 93 facilitates the identification of the use level beyond which a disturbance occurs and users' 94 satisfaction is affected. Notably, the literature on this subject has not provided evidence of a 95 significant relationship between use level and experience satisfaction (Shelby and Heberlein 96 1986; Manning 1999 for a review).

97 The effect of SCC on users' spatial distribution has been assessed by using two methods. The 98 first requires directly asking users what they will do in the case of high use level. This method quantifies the "current risk population" (following Navarro-Jurado et al., 2013), that is, the population of users who perceive the use level as high and intend to avoid the area in such circumstances. Second is the encounter norm assessment, that is, the number of encounters users would like to see at the same time. This approach permits the consideration of several thresholds' values for use level, such as a preferred number, acceptable number, and intolerable number of encounters (Manning and Vallière, 1999, these thresholds were termed evaluative dimensions by these authors). This method also documents the probability of visiting a site as a function of its use level.

This study investigated the answers to two main questions: i) how to assess the SCC of coastal recreational settings; and ii) how SCC affects the spatial distribution of users. To answer these questions, data from visitors and boats counts surveys and questionnairebased surveys documenting user's perceptions were collected and analyzed across sites.

111 First, factors explaining and characterizing crowding perception were identified. Second, 
factors affecting disturbance associated with use level and effectively perceived by users were assessed. Third, the relationship between these factors and the user's coping strategies in the case of high use level was studied. Lastly, SCC was assessed for each site by comparing use boats and visitors' counts with visitors' perception of use level obtained from questionnaire-based surveys.

\section{Materials and Methods}

\subsection{Study case}

New Caledonia is in tropical ecosystem approximately $1,500 \mathrm{~km}$ north-east of Australia. This French territory is surrounded by a large lagoon with many islets and reefs that are popular destinations for recreational users (Jollit, 2010; Gonson et al., 2016). In 2014, the population was approximately 180,000 and concentrated in the main city, Noumea, and surrounding cities (Dumbea, Paita, and Mont-Dore). The population has increased at an annual rate of $2.8 \%$ (ISEE, 2014).

MPAs with conservation goals have been created since 1981 on the closest islets and reefs to Noumea (Figure 1 - line 134). There are two MPA types, namely, natural reserves (NR) and sustainable management resource areas (SMRA), and both forbid extractive activities (fishing, shellfish collection, wood collection). NRs focuses on environmental conservation. SMRAs have economic development and environmental protection goals. For instance, the Maître islet hosts a hotel and kite surf school and is serviced by three shuttle transport companies. Amenities (e.g., permanent mooring, shelters, pontoon, and fireplaces) were installed on all the MPA islets to limit the impacts of recreational uses on the marine and terrestrial natural environments.

The six islets considered in this study differ in their geographical and managerial conditions. These differences offer a diversity of recreational conditions that can be formalized through the Recreational Opportunity Spectrum (ROS) (Clark and Stankey, 1979). According to the ROS semantic, a site is classified as modern when it is highly accessible, offers numerous amenities, and usually experiences a high use level; this is, for instance, the case of the SMRA islets like Maître. The NR islets are accessible by using the taxi-boat services operating 
within these sites and near Noumea, resulting in a moderate-to-high use level. NR islets are classified as semi-modern sites according to the ROS. The other islets are considered primitive (Mbo and MbeKouen) or semi-primitive (Pandanus) sites because managerial intervention is very limited and little or no amenities are available; these sites are less accessible and, as a result, have a low-to-moderate use level. Compared with the primitive islets, the semi-primitive islets are a shorter distance to the main urban center and experience a higher use level (Gonson et al. 2017).

\subsection{Data collection}

\subsubsection{Users' perception questionnaire-based survey}

A survey was designed to collect data on users' characteristics: i) their perception of crowding, ii) factors related to crowding that disturb them, and iii) their coping strategies when managing crowding situations. The questionnaires were administrated between November 2014 and March 2015 in face-to-face interviews with recreational users during their trip to the islet. One person (aged over sixteen) was interviewed within each sampled group. A group is defined as a party of several persons who arrived on and then left the islet in the same boat or taxi-boat and spent time together while on site.

The perception of crowding is subjective and person-specific. To analyze perceptions as a function of users' characteristics, individual information was collected during the survey, such as their frequency of visits to the islets, their experiences in the area (number of years visiting the lagoon facing Noumea), socio-professional category, home city, and gender. The users were also asked about the following: i) boat type, ii) activities undertaken within the group, iii) group size, iv) trip duration and v) whether islet quietness was a motivation for site selection. Inquiring about quiet as a motivation documents which recreational experience users seek during their trip.

The perception of crowding is generally measured on a Likert scale (i.e., nine possible categories) adapted by Heberlein and Vaske (1977). To simplify the answer and avoid preferences for a central "refuge" value (i.e., a tendency to select the median neutral value), scoring was restricted to four categories and adapted from Vaske and Shelby (2008). This 
adaptation was, for example, recommended by the French National Institute of Statistic and

169 Economic Studies and has been used in the literature (see Bergere and Le Berre, 2011;

170 Boncoeur et al. 2013; Brecard and De Luigi, 2016 for example).

171 Visitors were thus asked whether they felt the site was "not at all crowded," "slightly 172 crowded," "moderately crowded," or "extremely crowded." They were also asked to 173 estimate the number of visitors on the islet and number of boats around it at the time when 174 the questionnaire was administered. Crowding perception is often assessed in relation to the 175 perceived numbers of visitors or boats encountered by users during their trip. These 176 numbers were likely to differ from the actual number of boats and visitors present at the 177 site. Comparing the perceived number of boats and visitors estimated by users with the 178 actual number observed is administrated and should provide relevant information on the 179 dependence of crowding perception upon site, trip, and users' characteristics.

180 As defined in the introduction, SCC refers to the use level beyond which users' experience 181 quality decreases. Often associated with the number of visitors or boats, quality decrease of 182 user' experience might also depend on other events associated with crowding, like noise or 183 disrespectful behavior (e.g., untidiness in the campground and trampling on coral reef). 184 These criteria were termed disturbances in this study.

185 To increase the information regarding how users perceive crowding, the questionnaire 186 included an open-ended question asking the user to identify disturbances related to other 187 users. Among all possible disturbances, users were specifically asked whether the number of 188 boats and/or visitors was one. When the answer was yes, visitors were asked the following: 189 to evaluate the maximum number of visitors and boats they would prefer to see during their 190 trip on the islet and the acceptable and intolerable numbers of visitors and boats. The 191 acceptable threshold was the number above which there was a perceived disturbance 192 associated with use level. The intolerable number was the threshold that induced the user to 193 implement a coping strategy like displacement to another site. During the interview, the 194 user was reminded of their estimated number of boats and visitors and of their crowding 195 perception to increase the consistency of answers. 
196 Finally, all interviewees were asked to select a coping strategy, in the case where they had to manage a crowded situation on the islet they had planned to visit. The following answers were proposed: i) I have no coping strategy; ii) I will stop visiting the islet during the most crowded days (e.g., weekend days and holidays) and then cope by displacing, either iii) within the same islet or iv) to another islet. The users were free to not respond to this question and declare they did not know how they would cope. A total of 396 questionnaires were completed during five field trips operated between 9 a.m. and 5 p.m. The field trips were planned during weekend days because of the higher number of users compared with weekdays (Gonson et al., 2016), which is a concern for environmental managers. During the 2013 field work, it was observed that users did not perceive crowding during weekdays (Gonson 2017). Therefore, although the interviews conducted on weekdays would have provided additional information regarding crowding perceptions, they would also have added variability while contributing neither to identify factors affecting crowding perception nor to assess SCC. This point is further discussed in $\S$ 4.1.

\section{2.2.2. Boats and visitors count surveys}

218 Recreational boats were counted over a one year cycle: March 2013 to February 2014. In 219 total, 50 field trips stratified per day type (i.e., weekday or weekend) and per quarter were 220 undertaken. Day trips occurred between 8 a.m. and 4 p.m., and the duration was between 22130 minutes and one hour. The departure times and weather conditions of trips were 222 randomly selected within each stratum. At each islet, the overall number of boats observed 223 (motor boat, sail boat, dinghy, and jet-ski) was recorded. Dinghies differ from so-called 224 motor boats in that they are smaller than $5 \mathrm{~m}$ and the pilot sits at the rear of the boat 
holding the helm of the motor. Dinghies were not counted when only used by visitors to

226 shuttle between the main boat and the islet.

227 Additional counts of recreational boats and visitors on the islet were achieved by using the 228 same method between November 2014 and March 2015, before conducting interviews. 229 Counting visitors on the islet took between five and 30 minutes depending on islet size.

\section{$230 \quad$ 2.3. Data analysis}

\subsubsection{Data representativeness and consistency between 2013 and 2014}

Crowding perception may depend on factors relative to individual users, islet settings, or current number of boats. The mean number of boats per trip observed during the questionnaire survey in 2014 was compared with the mean number of boats per trip observed at each islet in 2013, based on a Kruskal-Wallis test. The consistency of the boat

239 The representativeness of the sample regarding the overall population of visitors was 240 assessed from the mean sampling rate over trips at each islet. This rate was the ratio between the number of visitors interviewed and total number of visitors observed during

244 2.3.2. Factors affecting estimation of use level and perception of crowding by 245 interviewees

246 To understand how factors related to user, trip, site and use level affect the estimation error 247 of crowding perception and SCC, perceived and observed numbers of boats and visitors were 248 analyzed.

249 The discrepancy between the numbers of visitors and boats perceived by users and their real 250 observed values depends on the users' perception (Kuentzel and Heberlein, 1992) and real 251 number of visitors and boats. The difference estimation error was computed and divided by 
the observed number of boats or visitors. The ratio, hereafter called the estimation error, is

253 written as follows: $\quad \alpha_{i}=\frac{N_{i}^{e s t}-N_{t_{i}}^{o b s}}{N_{t_{i}}^{o b s}}$

254 With $a_{i}$, the estimation error $N_{i}^{e s t}$ is the number of visitors (or boats) estimated by user $i$, and $N_{t_{i}}^{o b s}$ is the number of visitors (or boats) observed during the survey on the day $t_{i}$ when

256 user $i$ was interviewed. A positive (resp. negative) value of $a_{i}$ indicates an overestimation 257 (resp. underestimation) by user $i$.

258 A chi-squared test was used to test the effect of factors on crowding perception. A Kruskal259 Wallis test was used to test the effects of the same factors on the estimation error a for the 260 number of visitors and number of boats. The factors considered were either related to i) islet 261 factors such as islet identity, ROS category, and protection status (Figure 1); ii) user's trip, 262 that is, boat type, activity, on-site location, duration of the trip, and group size; iii) crowding, 263 that is, relative crowding level, quietness as an islet selection criterion, number of visitors 264 and/or boat perceived as a disturbance; and iv) user identity, that is, socio-professional 265 category, age, home city, gender, trip frequency, experiences in the lagoon. The relative 266 crowding level in iii) is a binary variable that is high (resp. low) if the number of users during 267 the 2014 survey exceeded (resp. was lower than) the median number of users observed in 268 2013. This binary variable was computed for the number of boats and number of visitors.

\section{2.3.3. Relationship between disturbances and coping strategies}

270 The relationships between coping strategies and disturbances based on boat type and islet 271 were explored through multiple correspondence analysis (MCA). Coping strategies and 272 disturbances were the active variables of the MCA. Boat types and islets were used as 273 illustrative variables and thus projected on the factorial axes to demonstrate their 274 relationships with the active variables without contributing to factorial axes. The 275 associations among the categories between the qualitative variables were tested by using a one-way analysis of variance for each factorial axis with respect to any category whether 277 active or illustrative, also termed test-values (additional details in Lebart et al. (1984) and 278 Pelletier and Ferraris (2000)). 


\section{2.3.4. Social carrying capacity assessment}

280 SCC was assessed by gauging the observed numbers of boats and visitors estimated from the 2812013 survey with respect to the preferred, acceptable, and intolerable threshold values for 282 these numbers obtained from the interviews (see subsection 2.2.1).

283 Each of the three value (respectively corresponding to preferred, acceptable, and intolerable 284 levels thresholds) was modified as follows to account for individual estimation error (see 285 section 2.3.2) (see eq. 1).

$$
E_{i}^{c}=E_{i}+\alpha_{i} E_{i}
$$

287 with $E_{i}^{c}$ as the modified estimation, $E_{i}$ is the estimation given by user $i$ for a given threshold, 288 and $\alpha_{i}$ is the estimation error. This ensures that $E_{i}^{c}$ relates to the actually observed numbers 289 and that the estimations from all users are consistent.

290 The numbers of boats and visitors on weekend days were estimated from the 2013 survey, 291 which was a year-round survey. However, visitors on the islets were only counted during the 2922014 survey. An estimate of the number of visitors at each islet and for 2013 weekend days 293 was obtained by multiplying the number of observed boats on weekend days during boat 294 counts in 2013 with the average group size and average proportion of visitors disembarking 295 on the islet observed during the 2014 survey. The latter averages were computed per boat 296 type. Notably, this estimate is an overestimate as all visitors do not disembark on the islet at 297 the same time.

298 These estimated numbers of boats and visitors were further divided by the surface area of 299 the islet for the number of visitors and surface of the mooring area for the number of boats. 300 Thus SCC was quantified in terms of density of visitors or boats. These estimates were then 301 compared with their respective preferred, acceptable, and intolerable thresholds calculated 302 from eq. (2); the comparison relied on a Wilcoxon test. 


\section{Results}

\subsection{Data representativeness and consistency between 2013 and 2014}

The sampling rate ranged from $13.6 \%$ on the Signal islet to $32.5 \%$ on the Mbe Kouen islet. The overall sampling rate among field trips and islets was $16 \%$. These rates are reasonably large to consider the samples as representative of the surveyed population during each field trip.

At each islet, the number of boats counted during the 2014 survey did not significantly differ from the boats counted during weekend days in 2013 (Kruskal-Wallis test, p>0.05) (Table 1 line 315). Thus, the crowding conditions observed in 2014 can be hypothesized as being representative of those observed during the weekend days in 2013. By contrast, in 2013, the number of boats per trip during weekdays was almost ten times lower than during weekend days.

Likewise, the proportion of users per boat type and per islet did not differ between 2014 and 2013 (Mann-Whitney test, $p>0.05$ ), except for the Maître islet, where the proportions of sailboats and motor boats were higher in 2014 than in 2013 with, by contrast, a lower proportion of taxi-boat users.

Regarding trip duration, notably, on the islets most proximal to Noumea (Maître, Larégnère, and Signal, which are MPA), most visitors do not stay overnight; this result is in contrast with the unprotected islets where visitors usually spend at least one night. Thus, the experience sought by users is likely to differ between the MPAs and unprotected islets also because of the distance to the city.

\subsection{Factors affecting crowding perception}

Estimation error is highly variable among users, ranging from -0.88 to 7.11 for the number of visitors and from -0.86 to 2.57 for the number of boats. Estimation error of the number of visitors was found to significantly depend on the islet and its corresponding ROS category, on-site location of users, and home city (Table 2 - line 335). Specifically, for boat number, the estimation error significantly varied according to user's experience in the area; notably, 
this was the case for the visitors and boats estimation error according to the observed use level compared with the usual one. Hence, at a modern islet, the number of visitors was overestimated by $13 \%$; at semi-modern sites, it was underestimated (-23\%). Users interviewed on the boat underestimated the number of visitors by $32 \%$ when on the leeward side of the islet; by contrast, where users concentrated, they slightly overestimated it (3\%). Users living outside New Caledonia, considered tourists, overestimated the number of visitors (31\%), and Noumea residents underestimated it $(-13 \%)$. Newcomers to the islet strongly underestimated (-48\%) the number of boats, whereas users with more experience in the area only slightly underestimated this number, and their estimation error was then not significant: ranging from $-21 \%$ to $-12 \%$. At relatively low use levels, the estimation error was lower than at higher use levels: a $-20 \%$ versus $-27 \%$ underestimate for the number of boats and a $0.1 \%$ overestimation versus $5 \%$ underestimation for the number of visitors. Among the factors considered, protection status, boat type, activity, trip duration, group size, quietness as islet selection criterion, number of boats or visitors considered a disturbance, age, socio-professional category, and gender did not significantly affect the estimation error for the number of boats or visitors.

Overall, $58 \%$ of the interviewed users felt not crowded at all, $26 \%$ slightly crowded, $14 \%$ moderately crowded, and $3 \%$ extremely crowded. These proportions significantly differed between islets, ROS categories, boat types, and user's location on the islet. These proportions also depended on the relative use level: i) whether the interviewees were looking for quietness or not, ii) whether they considered the number of visitors or boats as a disturbance or not, and iii) irrespective of user age (Table 3 - line 352).

For modern islets, the proportion of users feeling not crowded at all was higher than at other ROS categories' islets. For semi-modern islets, the proportion of users feeling slightly and moderately crowded was high. For semi-primitive islets, the proportion of users feeling moderately crowded was high.

Crowding perception by users did not significantly differ between protection status. Users who arrived in motor boats or dinghies felt more crowded than users using other boat types. Jet-skiers felt less crowded on average. Users located on the leeward side of the islet often 
felt more crowded than users on boats or on the windward side of the islet. When use level was high, users logically felt more crowded.

The proportion of users feeling crowded (either moderately or extremely) was much higher for users choosing the islet for its quietness. When users looking for quietness were not satisfied with the actual use level, they tended to feel crowded more often. Crowding perception was higher for users potentially disturbed by the number of visitors and, to a lesser extent, for users disturbed by a large number of boats. By contrast, crowding perception was much lower for interviewees for which the number of boats or visitors was not considered a disturbance. Finally, younger users felt on average more crowded than older users. Among all factors tested, socio-professional category, place of residence, gender, experience in the area, and trip frequency did not affect crowding perception.

The most cited disturbances were the number of visitors (66\%) and boats (53\%). Crowding perception was observed to be highly correlated with use level. Other most cited disturbances were noise (26\% cites), disrespectful behaviors (either with regarding the visitors or environment) (22\%), and speed activities (e.g., jet-skiing, kite surfing, and windsurfing) (13\%) (Figure 2 - line 379). Additional disturbances, namely, the presence of waste, pets, beached boats, and traffic along with insufficient space and extant infrastructure were cited by less than $8 \%$ of users. Perceptions related to these less cited disturbances contrasted among users, for example, extant infrastructure on the islet was considered a disturbance and a means of enhancing space and limiting islet saturation.

\subsection{Relationship between disturbing criteria and coping strategies}

The first axis of the factorial plan explained most of the data variance ( $89 \%$ versus $6 \%$ for the second axis) (Figure 3 - line 387). The first dominant axis distinguished users disturbed by a high number of visitors or boats and who would use displacement as a coping strategy, either within site or between sites, from users responding to other disturbances or not responding to any disturbance. Consequently, these users never displaced. Users potentially displacing generally arrived by motorized boat and located at less accessible islets. Sailboats did not implement any coping strategy. 
For users disturbed by a large number of visitors, the displacement coping strategy was likely to occur within the islet. This was preferentially observed at the Mbo and Signal islets and, in particular, for taxi-boat users and dinghies. The within site displacement strategy was more frequently observed at larger islets. At the islets nearest to the coast (Maître, Pandanus and Larégnère), users did not implement any coping strategy (displacement or visiting on less crowded days).

\subsection{Social carrying capacity assessment}

Among users disturbed by a high number of visitors or boats, a large proportion could estimate either a number of boats or number of visitors for each evaluation dimension (Figures 4 and 5 - line 398). This answer rate was generally higher for low values, that is, less crowded islets, and for the preferred and acceptable threshold values.

Except for the Pandanus and Mbo sites, the observed use (i.e., boat or visitors) density was significantly higher than the users' preferred threshold values (Figures 4 and 5). At Signal Is., observed boat density was significantly lower than the intolerable threshold value and comparable to the acceptable threshold value (Figure 4), but boat and visitor densities did not significantly differ from the intolerable threshold value.

For the Maître, Larégnère, and Mbe Kouen islets, boat and visitor densities were similar in distribution to intolerable threshold values but could not be statistically distinguished from acceptable values. Thus, at these four islets, the SCC was reached. On the Maître, Larégnère and Mbe Kouen islets, this phenomenon might result in implementing coping strategies either for the boats' or visitors' density. By contrast, on Signal, no coping strategy was likely to be implemented based on the interview results.

9 For the Pandanus Islet, the observed user density for visitors and boats did not significantly differ from the threshold values. Thus, on this islet, SCC was reached only during the most crowded days (e.g., weekends during holidays). Mbo was the only islet where the observed visitors and boats densities were significantly lower than intolerable threshold values and did not significantly differ from preferred threshold values. Notably, on this islet, the 
414 acceptable boat density was significantly higher than those observed. Thus, the Mbo islet

\section{Discussion}

\subsection{Social carrying capacity and its link with spatial distribution of} recreational users depend on settings and boat type

Based on quantitative and complementary data on the recreational users, the factors affecting the perception of crowding by boaters and visitors were investigated, and an assessment of SCC of recreational outdoor settings in an MPA network was proposed. The results showed that crowding perception was firstly and clearly explained by users' density. However, as demonstrated in the literature, crowding perception and sites' SCC are also affected by the expected users' density (Manning, 1985; Inglis et al., 1999), user experience (Arnberger and Brandenburg, 2007; Inglis et al., 1999), and setting characteristics (Cole and Hall, 2009). ROS setting classes, defined by social and managerial conditions, were helpful to assess SCC. The effect of SCC on recreational users' spatial distribution depended on boat type and their displacement capacity, for example, motorboat users were more willing to displace than sailboats users. In addition to use level, specific disturbances, such as noise and disrespectful behaviors, can also determine the implementation of a coping strategy. Within the lagoon facing Nouméa, Gonson et al. (2017) demonstrated that site accessibility was the primary selection criterion for the choice of a recreational setting, but users can also consent to spend more sailing time to visit less accessible islets if they prefer low use levels. The results in this study indicate that in addition, the choice of an adequate setting is more determined by the expectations of individuals within a group looking for a specific experience than by the user and boat type category. In addition, the high proportion of users able to identify threshold values of use level (preferred, acceptable, and intolerable visitor and boat densities) further suggests that the quality of experience sought by most 
recreational users strongly depends on use level. Consequently, and related to the concept of SCC, use level leads to a spatial distribution within and among recreational settings that is 443 specific to use categories. Hence, Maître Islet is a modern (ROS category) site and characterized by a heavy use level with a higher proportion of tourists and of speed activity users than at other sites (Gonson et al., 2017). Thus, visitors of this islet perceived less crowding, either because they have less experience in the area or are not particularly seeking quietness. Moreover, they are less likely to go to other sites when they do perceive crowding, because tourists have less displacement capacity. Speed activities are practiced away from the crowded mooring areas and beaches and thus unlikely to displace. In addition, such islets being particularly accessible from Nouméa, a high use level is likely to be expected by users. Consequently, use level in this islet continues to increase at a high rate (Gonson et al., 2016), whereas the SSC has already been reached. Similar evolutions are to be expected at two other islets in the same area categorized as modern sites (not investigated in this study, see Gonson 2017): Unlike Maître, which depends on speed and tourism, these islets host activities that specifically rely on environmental quality, for example, snorkeling on a submarine trail for Canard Islet and relatively large Signal islet, the SCC is more likely to be reached on a small islet like Larégnère 469 Islet, where the number of visitors is actually considered the major disturbance associated 
with crowding. The number of sailboats was found to be greater around this small islet than

471 around Signal islet. Sail boat displacement capacity is limited by weather conditions and a 472 slow pace, compared with motor boats, which may also explain why sailboats do not show 473 displacement coping strategies. In addition, sailors are less affected by visitors' density. 474 Indeed, when confronted to crowded islets, as they often stay overnight (Gonson, 2017), 475 they can disembark when fewer visitors are on the islet.

476 For the semi-primitive Pandanus Islet, crowding perception was found to be similar to semi477 modern islets, although user density was much lower. This result might be explained by the 478 lower expected numbers of boats and visitors (Manning, 1985; Inglis et al., 1999). 479 Surprisingly, at this islet, observed users' densities were rated as comparable to the 480 "preferred" threshold but also sometimes considered as intolerable as a function of the dayto-day highly variable use levels. Variable weather conditions, seasons, and holidays have been demonstrated to influence the spatial distribution of users (Kuentzel and Heberlein, 1992; Smallwood et al., 2012a; Smallwood et al., 2012b; Smallwood, 2011; Gray et al., 2010; Dalton et al., 2010; Widmer and Underwood, 2004; Balaguer et al., 2011; Navarro-Jurado et al., 2013), especially in this area (Gonson et al., 2016). Such variability interferes with crowding perception and SCC assessment.

In this study, SCC was assessed based on a year-round survey, encompassing a wide range of conditions. It can be hypothesized that conditions fostering a high use level at most accessible sites result in higher numbers of users at semi-primitive islets through the displacement of users most disturbed by crowding. This increase in user number is also concurrent with a demographic increase in the proximate towns (Gonson et al 2016) where several marinas are installed. This situation entails more variable user numbers than at other islets, resulting in contrasted crowding perceptions among users.

At primitive islets, the proportion of users perceiving crowding is similar to semi-modern and semi-primitive islets; however, the distribution of use levels matches quite well with that of the preferred threshold value, indicating that the SCC is not reached on the primitive islets.

97 The high proportion of sail boats, which are less affected by crowding and have fewer 498 displacement coping strategies, could explain this result. That is, because these users are 
most often overnighters, cognitive coping strategies (e.g., staying on the boat during the most crowded period of the day) are likely to occur and diminish the crowding perception (Shelby and Heberlein, 1986).

Our results may be related to the concept of limit acceptable change (LAC), which refers to the amount of change, in this case, the numbers of visitors deemed acceptable by users. LAC has been studied in recreational settings (McCool, 1994), protected areas (McCool, 1996), and coastal areas for recreational boating activity (Diedrich et al., 2011). In this study, the number of users increased much more at the most accessible islets than at the primitive and semi-primitive islets (Gonson et al. 2016). In parallel, our results showed that SCC was more often reached on these most accessible islets. These findings highlight the link between SCC and LAC.

\subsection{Assessing Social Carrying Capacity by integrating interview and count} data

In this study, the survey data (usually used for assessing SCC in recreational settings) were analyzed together with boat-count data obtained from a year-round survey. Navarro-Jurrado et al., (2012) identified a threshold value for visitors' density to study SCC on Spanish beaches. However, most studies have been based on the number of divers (Bentz et al., 2015; Szuster et al., 2011), snorkelers (Needham et al., 2011), visitors (Manning et al., 2002; Needham et al., 2008 ; Kim and Shelby, 2011), or boats (Needham et al., 2011; Bentz et al., 2015), beyond which, the perception of crowding either increases (Kim and Shelby, 2011) or is associated with an unacceptable use level (Manning et al., 2002 ; Needham et al., 2008; Bentz et al., 2015).

Other setting characteristics have been demonstrated to affect users' experience (Cole and Hall, 2009) and crowding perception (see Manning, 1999 for a review), such as the surface available to users, as demonstrated in the studies based on the photography of mooring areas (Needham et al., 2011) or trails (Manning and Valliere, 1999; Manning et al., 2002; Needham et al., 2004; Kim and Shelby, 2011). By considering density instead of number, the comparison among sites was easier and a better understanding of the influence of site 
characteristics other than site surface area on crowding perception, and thus on SCC, was 528 possible.

529 Monitoring recreational use in marine environments is difficult and data are often absent or 530 scarce (Smallwood et al., 2011). Consequently, few studies have been able to quantitatively 531 compare information on crowding perception and SCC with visitor- or boat-count data 532 representative of intra-annual variability. Use level data considered in the literature has 533 often corresponded to average or elevated numbers of users at year scale (Leujak and 534 Ormond, 2007; Bentz et al., 2015; Salerno et al., 2013), rather than at the day level, where 535 the individual perception of crowding occurs, thus making it the appropriate temporal scale 536 for crowding perceptions.

537 We acknowledge that the 2014 interviews were conducted only on weekends. Based on 5382013 observations (Gonson 2017), weekday users did not perceive any crowding. Interviews 539 conducted on weekdays would provide additional information regarding crowding 540 perceptions, mainly to identify which users are likely to prefer going out on the lagoon on 541 weekdays as a coping strategy with respect to anticipated weekend crowding. But they 542 would not provide information on crowding situations and factors affecting the perception 543 of these situations. Notably, in 2013 and in previous years (Gonson et al. 2016), use level on 544 weekdays was on average ten times lower than during weekends. Regarding SCC assessment, additional interviews on weekdays would primarily affect the distribution of

546 preferred threshold values but should not affect that of intolerable threshold values.

547 Shelby and Heberlein (1986) developed a scale to assess the SCC of a site based on the 548 proportion of users with a given crowding perception. Our approach relied on the joint use 549 of count and interview data in addition; the purpose was to independently evaluate the 550 users' estimation of the use level and correct their estimation as well as ii) assess the SCC of 551 recreational outdoor settings and its potential effect on users' spatial distribution. SCC was 552 assessed based on users' estimations of use level for several evaluative dimensions 553 (preferred, acceptable, and intolerable) and annually representative use level data at the day 554 scale. This quantitative approach, with its several evaluative dimensions, enabled this study 555 to define a meaningful threshold for use level at a set of sites with distinct characteristics. 
556 Furthermore, SCC assessment accounts for the use level varying between days depending on weather conditions, season, and day type (Gonson et al., 2016), by considering data from a

558

559

560

561

562

563

564 579 impact.

580 For social impacts, activities undertaken by users in such multi-use managed areas can be 581 conflicting (Widmer and Underwood, 2004). Hammit and Cole (1998) found that actual or 582 potential conflicts among uses are an additional factor contributing to crowding perception. 583 Thus, management measures for limiting interactions between conflicting practices should 
584 be considered and could include spatial and/or temporal regulation of activities. For

585

586

587 example, speed activities, which are most disturbing to visitors who value quietness, could be banned on the leeward side of the islet, where beach and snorkeling activities take place. Another measure could be to ban the most disturbing activities when use level is expected to be high. In the same area, such conditions were identified to occur during the warm season and on weekends (Gonson et al., 2016). For example, this ban might apply to jet-ski activity, the second most cited disturbance after user density.

At semi-modern islets, in this study, the NRs, the majority of islet users were New Caledonian residents. Eder and Arnberger (2012) found that resident users were more attached to nearby natural settings and more concerned regarding their utilization (Eder and Arnberger, 2012) and natural state (Cole and Hall, 2009). Management actions, such as information and education, should efficiently reduce the impacts of uses on the natural state.

Primitive and semi-primitive islets were characterized by lower use densities. Although they are not subject to regulations, the pressures related to recreational uses were lower at these sites than at NRs (Gonson et al., 2017). Users tended to visit these sites for quietness (Gonson et al., 2017). Unfortunately, the increasing number of inhabitants in nearby cities and propagation of users from more crowded islets are likely to increase user densities in the near future. Because practices are not regulated at these sites, the effects on the natural environment and crowding perception are hence expected to increase. Additionally, the relationship between use level and natural impacts is curvilinear, that is, a relatively small increase in pressure causes a marked impact where the pressure level has previously been low (Cole, 2004; Milazzo et al., 2002).

607 These unprotected islets, especially semi-primitive islets are quite accessible for proximal 608 cities users and they have indeed experienced an increasing pressure level in recent years 609 (Gonson et al., 2017). Limiting access to these islets could be desirable to preserve 610 environmental quality and offer a quiet wilderness experience for users. Such management 611 actions were recently undertaken at Mbe Kouen islet, where landing on the islet is forbidden 
612

during the bird nesting period. Assessing the effectiveness of this measure would show the relevance of this measure and facilitate its application on other islets.

Several studies have shown that evidence of human-induced effects, such as the presence of litter and trampling (both underwater and inland), increased the perception of crowding by users (see Ormsby et al., 2004 for a review). Limiting these pressures should decrease impact and increase SCC. Amenities and built facilities (e.g., trash bins and toilets) are complementary management options but may decrease the enjoyment of users looking for a wilderness experience and increase their crowding perception (Shafer et al., 1998). A balance between use regulation and built facilities must be found in such MPAs to satisfy the wilderness experience aspect and limit the ecological impacts. Studying the impact of recreational uses on ecosystems through collection and joint analysis of appropriate ecological data should be undertaken concurrently with SCC assessment for practice regulation and to assess users' enjoyment of their trip-especially within MPAs.

This type of work was undertaken within the same AMBIO research project at the scale of the south-west lagoon of New Caledonia, an area encompassing the one in this study. The aim was to analyze data on sensitive species groups (fish and birds) and habitats (coral reefs and seagrass) to find evidence of the possible effects of recreational practices (fishing, anchorage) (Gonson 2017) and infrastructure.

\section{Conclusion}

With the increase in the number of recreational users in coastal areas and MPAs, crowding has become a major concern for management and raises the issues of SCC. However, crowding perception and its link with users' spatial distribution and SCC has been poorly documented. In this study, boat counts, visitor counts, and interviews were used to assess SCC at several sites corresponding to distinct outdoor recreational settings and explore its relationship with users' spatial distribution. User's crowding perception and several evaluative dimensions of crowding were assessed from the questionnaires. The ROS was found to be relevant to address and discuss SCC-related issues, together with major explanatory factors such as user's experience and expectations regarding use level. 
640 Furthermore, in these recreational settings, SSC was found to also depend on the magnitude

641 of change in use level. Boat type was identified as a determining factor for user's spatial 642 distribution, because this factor is tightly linked to users' displacement capacity. Use level 643 was the main criterion associated with crowding perception, either in number of boats or 644 visitors. The outcomes of this study indicate critical factors for management measures aimed 645 at increasing SCC, thereby enhancing recreational users' satisfaction and reducing the risk of 646 conflicts between users.

\section{6. Acknowledgement}

648 This study forms part of a $\mathrm{PhD}$ in the $\mathrm{AMBIO}$ project funded by the Conservatoire des 649 Espaces Naturels, the three provinces and the Government of New Caledonia, and the 650 French Ministry of Ecology and Sustainable Development (12/1219969/C).

\section{References}

652 Arnberger, A., Brandenburg, C., 2007. Past On-Site Experience, Crowding Perceptions, and 653 Use Displacement of Visitor Groups to a Peri-Urban National Park. Environ. Manage. 40, 34654 45. doi:10.1007/s00267-004-0355-8

655 Balaguer, P., Diedrich, A., Sardá, R., Fuster, M., Cañellas, B., Tintoré, J., 2011. Spatial analysis 656 of recreational boating as a first key step for marine spatial planning in Mallorca (Balearic 657 Islands, Spain). Ocean Coast. Manag. 54, 241-249. doi:10.1016/j.ocecoaman.2010.12.002

658 Bentz, J., Rodrigues, A., Dearden, P., Calado, H., Lopes, F., 2015. Crowding in marine 659 environments: Divers and whale watchers in the Azores. Ocean Coast. Manag. 109, 77-85. 660 doi:10.1016/j.ocecoaman.2015.03.001

661 Bergere, H., Le Berre, S., 2011. Définition et étalonnage d"un système d"évaluation de la 662 capacité de charge de I"île de Port-Cros. Sci. reports Port-Cros Natl. Park 25, 81-104.

663 Boncoeur J. , Alban F., Brigand L., Coic F., Guégan C., Guingot M., Le Berre S., Le Corre N., 664 Levi L., Meunier M., Pagès C., Peuziat I., Voltaire L., 2013. Evaluation et suivi des effets 665 économiques de la fréquentation des sites littoraux et insulaires protégés : application aux 666 îles Chausey et au Mont Saint-Michel. Programme LITEAU III. Projet de recherche BECO. 
667 Rapport final. Publications électroniques Amure, Série Rapports R-33-2013, 100p.

668 (Disponible: http://www.umr-amure.fr/electro_rapports_amure/R_33_2013.pdf)

669 Brécard, D., Luigi, C.D.E., 2016. Fréquentation touristique de Port-Cros et Porquerolles : les 670 enseignements de la base de données Bountîles. Sci. Reports Port-Cros Natl. Park, 30: 65-94

671 Brown, P.J., Driver, B.L., McConnell, C., 1978. The opportunity spectrum concept and 672 behavioral information in outdoor recreation resource supply inventories: background and 673 application. National workshop on integrated inventories of renewable natural resources, 674 Tucson, Arizona, 8-12 jan.

675 Bujosa, A., Riera, A., Hicks, R.L., McConnell, K.E., 2010 Congestion and site choice: beach 676 recreation in the Mediterranean.

677 Chen, C.L., Teng, N., 2016. Management priorities and carrying capacity at a high-use beach 678 from tourists" perspectives: A way towards sustainable beach tourism. Mar. Policy 74, 213679 219. doi:10.1016/j.marpol.2016.09.030

680 Clark, R.N., Stankey, G.H., 1979. The Recreation Opportunity Spectrum : A Framework for 681 Planning , Management , and Research. Gen. Tech. Rep. 39. 682 doi:10.1177/004728758001900244

683 Cole, D.N., 2004. Impacts of Hiking and Camping on Soils and Vegetation: A Review. Environ. 684 Impacts Ecotourism 41-60. doi:10.1017/CBO9781107415324.004

685 Cole, D.N., Hall, T.E., 2009. Perceived effects of setting attributes on visitor experiences in 686 wilderness: variation with situational context and visitor characteristics. Environ. Manage. 687 44, 24-36. doi:10.1007/s00267-009-9286-8

688 Dalton, T., Thompson, R., Jin, D., 2010. Mapping human dimensions in marine spatial 689 planning and management: An example from Narragansett Bay, Rhode Island. Mar. Policy 690 34, 309-319. doi:10.1016/j.marpol.2009.08.001

691 Davenport, J., Davenport, J.L., 2006. The impact of tourism and personal leisure transport on 692 coastal environments: A review. Estuar. Coast. Shelf Sci. 67, 280-292. 693 doi:10.1016/j.ecss.2005.11.026

694 Davis, D., Tisdell, C., 1995. Recreational scuba-diving and carrying capacity in marine 695 protected areas. Ocean Coast. Manag. 26, 19-40. doi:10.1016/0964-5691(95)00004-L 
De Santo, E.M., 2013. Missing marine protected area (MPA) targets: How the push for quantity over quality undermines sustainability and social justice. J. Environ. Manage. 124,

698

699

700

701

702

703

704

705

706

707

708

709

710

711

712

713

714

715

716

717

718

720

723

719 Gonson, C., Pelletier, D., Alban, F., Giraud-Carrier, C., Ferraris, J., 2017. Influence of settings 721 Areas. J. Environ. Manage. 200, 170-185. doi:10.1016/j.jenvman.2017.05.051

722 Gray, D.L., Canessa, R., Rollins, R., Keller, C.P., Dearden, P., 2010. Incorporating recreational 724 Columbia, Canada. Environ. Manage. 46, 167-80. doi:10.1007/s00267-010-9479-1 137-146. doi:10.1016/j.jenvman.2013.01.033

Diedrich, A., Balaguer Huguet, P., Tintoré Subirana, J., 2011. Methodology for applying the Limits of Acceptable Change process to the management of recreational boating in the Balearic Islands, Spain (Western Mediterranean). Ocean Coast. Manag. 54, 341-351. doi:10.1016/j.ocecoaman.2010.12.009Diedrich, A, Tintoré, J. 2012. Multi-method approach to exploring social-ecological dimensions in a Mediterranean suburban beach setting. Coastal Management 40:301-311.

Duedall, I. W., \& Maul, G. A., 2005. Demography of Coastal Populations. In Maurice L. Schwartz (Ed.), Encyclopedia of Coastal Science (pp. 368-374). Springer Netherlands. doi:10.1007/1-4020-3880-1_115

Eder, R., Arnberger, A., 2012. The influence of place attachment and experience use history on perceived depreciative visitor behavior and crowding in an urban National Park. Environ. Manage. 50, 566-580. doi:10.1007/s00267-012-9912-8

Gonson, C. 2017. Integration of recreational uses and marine biodiversity for assessing nd managing coastal areas: Application to New Caledonian Marine Protected Areas based on use monitoring and decision-support modelling. PhD dissertation, University Pierre et Marie Curie, $\quad$ Paris. $264 \quad$ p. $\quad$ https://tel.archives-ouvertes.fr/tel-01633543. http://archimer.ifremer.fr/doc/00391/50261/

Gonson, C., Pelletier, D., Gamp, E., Preuss, B., Jollit, I., Ferraris, J., 2016. Decadal increase in the number of recreational users is concentrated in no-take marine reserves. Mar. Pollut. Bull. 107, 144-154. doi:10.1016/j.marpolbul.2016.04.007 20 management and protection status on recreational uses and pressures in Marine Protected 23 users into marine protected area planning: a study of recreational boating in British 
725 Hammit, W.E., Cole, D.N., 1998. Wildlife Recreation. Ecology and Management, $2^{\text {nd }}$ ed. John 726 Wiley \& Sons, Inc., New York.

727 Hardiman, N., Burgin, S., 2010. Recreational impacts on the fauna of Australian coastal 728 marine ecosystems. J. Environ. Manage. 91, 2096-2108. doi:10.1016/j.jenvman.2010.06.012

729 Heberlein, T., Vaske, J.J., 1977. Crowding and visitor conflict on the Bois Brule River. Report 730 WISC WRC 77-04, University of Wisconsin Water Resource Center, Madison, WI.

731 Inglis, G.J., Johnson, V.I., Ponte, F., 1999. Crowding norms in marine settings: A case study of 732 snorkeling on the great barrier reef. Environ. Manage. 24, 369-381. 733 doi:10.1007/s002679900240

734 Jollit, I., Léopold, M., Guillemot, N., David, G., Chabanet, P., Lebigre, J.M., Ferraris, J., 2010. 735 Geographical aspects of informal reef fishery systems in New Caledonia. Mar. Pollut. Bull. 61, 736 585-97. doi:10.1016/j.marpolbul.2010.06.033

737 Kim, S.-O., Shelby, B., 2011. Effects of Information on Perceived Crowding and Encounter 738 Norms. Environ. Manage. 47, 876-884. doi:10.1007/s00267-011-9654-z

739 Kuentzel, W., Heberlein, T., 1992. Cognitive and behavioral adaptations to perceived 740 crowding: A panel study of coping and displacement. J. Leis. Res. 24, 377-393.

741 Lebart, L., Morineau, A., Warwick, K.., 1984. Multivariate descriptive statistical analysis. 742 Correspondence analysis and related techniques for large matrices. John Wiley \& Sons, New 743 York.

744 Leujak, W., Ormond, R.F.G., 2007. Visitor perceptions and the shifting social carrying capacity 745 of South Sinai's coral reefs. Environ. Manage. 39, 472-89. doi:10.1007/s00267-006-0040-1

746 Lime, D., Stankey, G., 1971. Carrying capacity: maintaining outdoor recreation quality. 747 Recreat. Symp. Proc.

748 Lindberg, K., Mccool, S., Stankey, G., 1996. Rethinking Carrying Capacity. Ann. Tour. Res. 24, $749 \quad 461-465$.

750 Manning, R., Lawson, S., Newman, P., Laven, D., Valliere, W., 2002. Methodological Issues in 751 Measuring Crowding-Related Norms in Outdoor Recreation. Leis. Sci. 24, 339-348. 752 doi:10.1080/01490400290050781 
753 Manning, R.E., 1999. Crowding and carrying capacity in outdoor recreation: From normative 754 standards to standards of quality. Leis. Stud. Prospect. twenty-first century.

755 Manning, R.E., 1985. Crowding norms in backcountry settings: a review and synthesis. J. Leis. 756 Res. 17, 75-89.

757 Manning, R.E., Valliere, W.A., 1999. Crowding Norms: Alternative Measurement Approaches.

758 Leis. Sci. 21, 97-115. doi:10.1080/014904099273174

759 Manning, R.E., Valliere, W.A., 2001. Coping in Outdoor Recreation: Causes and 760 Consequences of Crowding and Conflict Among Community Residents. J. Leis. Res. 33, 410761426.

762 Mauerhofer, V., 2013. Social capital, social capacity and social carrying capacity: Perspectives 763 for the social basics within environmental sustainability. Futures 53, 63-73. 764 doi:10.1016/j.futures.2013.08.006

765 McCool, S., 1994. Planning for Sustainable Nature Based Development. Tour. Recreat. Res. 766 19. doi:10.1080/02508281.1994.11014708

767 Milazzo, M., Chemello, R., Badalamenti, F., Riggio, R.C., Riggio, S., 2002. The impact of 768 human recreational activities in marine protected areas: What lessons should be learnt in 769 the Mediterranean sea? Mar. Ecol. 23, 280-290. doi:10.1111/j.1439-0485.2002.tb00026.x

770 Moscardo, G., Green, D., Greenwood, T., 2001. How great is the Great Barrier Reef! Tourists' 771 knowledge and understanding of the World Heritage status of the Great Barrier Reef. Tour.

772 Recreat. Res. 26, 19-25. doi:10.1080/02508281.2001.11081173

773 Navarro Jurado, E., Damian, I.M., Fernández-Morales, A., 2013. Carrying Capacity Model 774 Applied in Coastal Destinations. Ann. Tour. Res. 43, 1-19. doi:10.1016/j.annals.2013.03.005

775 Navarro Jurado, E., Tejada Tejada, M., Almeida García, F., Cabello González, J., Cortés 776 Macías, R., Delgado Peña, J., Fernández Gutiérrez, F., Gutiérrez Fernández, G., Luque 777 Gallego, M., Málvarez García, G., Marcenaro Gutiérrez, O., Navas Concha, F., Ruiz de la Rúa, 778 F., Ruiz Sinoga, J., Solís Becerra, F., 2012. Carrying capacity assessment for tourist 779 destinations. Methodology for the creation of synthetic indicators applied in a coastal area. 780 Tour. Manag. 33, 1337-1346. doi:10.1016/j.tourman.2011.12.017 
781 Needham, M.D., Rollins, R.B., Wood, C.J.B., 2004. Site-specific encounters, norms and 782 crowding of summer visitors at alpine ski areas. Int. J. Tour. Res. 6, 421-437. 783 doi:10.1002/jtr.504

784 Needham, M.D., Szuster, B.W., Bell, C.M., 2011. Encounter norms, social carrying capacity 785 indicators, and standards of quality at a marine protected area. Ocean Coast. Manag. 54, 786 633-641. doi:10.1016/j.ocecoaman.2011.06.004

787 Needham, M.D., Tynon, J.F., Ceurvorst, R.L., Collins, R.L., Connor, W.M., Culnane, M.J.W., 788 2008. Recreation Carrying Capacity and Management at Pupukea Marine Life Conservation 789 District on Oahu, Hawaii Final Report.

790 Orams, M., 1999. Marine tourism: Development, Impacts, and Management., Routledge. ed. 791 Psychology Press, London.

792 Ormsby, J., Moscardo, G., Pearce, P., Foxlee, J., 2004. A review of research into tourist and 793 recreational uses of protected natural areas. Great Barrier Reef Marine Park Authority, 794 Townsville.

795 Pelletier D., Ferraris J., 2000. A multivariate approach for defining fishing tactics from 796 commercial catch and effort data. Canadian Journal of Fisheries and Aquatic Sciences 57, 51797 65. doi: 10.1139/cjfas-57-1-51.

798 Priskin, J., 2003. Tourist perceptions of degradation caused by coastal nature-based 799 recreation. Environ. Manage. 32, 189-204. doi:10.1007/s00267-002-2916-z

800 Salerno, F., Viviano, G., Manfredi, E.C., Caroli, P., Thakuri, S., Tartari, G., 2013. Multiple 801 Carrying Capacities from a management-oriented perspective to operationalize sustainable 802 tourism in protected areas. J. Environ. Manage. 128, 116-25. 803 doi:10.1016/j.jenvman.2013.04.043

804 Saveriades, A., 2000. Establishing the social tourism carrying capacity for the tourist resorts 805 of the east coast of the Republic of Cyprus. Tour. Manag. 21, 147-156. doi:10.1016/S0261806 5177(99)00044-8

807 Shafer, C.S., Inglis, G.J., 2000. Influence of social, biophysical, and managerial conditions on 808 tourism experiences within the Great Barrier Reef World Heritage Area. Environ. Manage. 809 26, 73-87. doi:10.1007/s002670010072 
810 Shafer, C.S., Inglis, G.J., Johnson, V.Y., Marshall, N. a, 1998. Visitor experiences and perceived 811 conditions on day trips to the Great Barrier Reef. CRC Reef Research Centre Technical Report 812 No. 21, CRC Reef Research Centre, Townsville. 76 pp.

813 Shelby, B., Heberlein, T. a., 1986. Carrying capacity in recreation settings, Oregon sta. ed. 814 Corvallis.

815 Shelby, B., Heberlein, T. a., 1984. A conceptual framework for carrying capacity 816 determination. Leis. Sci. 6, 433-451. doi:10.1080/01490408409513047

817 Shelby, B., Vaske, J.J., Heberlein, T. a., 1989. Comparative analysis of crowding in multiple 818 locations: results from fifteen years of research. Leis. Sci. 11, 269-291.

819 Shivlani, M.P., Suman, D.O., 2000. Dive operator use patterns in the designated no-take 820 zones of the Florida Keys National Marine Sanctuary (FKNMS). Environ. Manage. 25, 647821659.

822 Smallwood, C.B., Beckley, L.E., 2012a. Spatial distribution and zoning compliance of 823 recreational fishing in Ningaloo Marine Park, north-western Australia. Fish. Res. 125-126, 824 40-50. doi:10.1016/j.fishres.2012.01.019

825 Smallwood, C.B., Beckley, L.E., Moore, S. a., 2012b. An analysis of visitor movement patterns 826 using travel networks in a large marine park, north-western Australia. Tour. Manag. 33, 517827 528. doi:10.1016/j.tourman.2011.06.001

828 Smallwood, C.B., Beckley, L.E., Moore, S. a., Kobryn, H.T., 2011. Assessing patterns of 829 recreational use in large marine parks: A case study from Ningaloo Marine Park, Australia. 830 Ocean Coast. Manag. 54, 330-340. doi:10.1016/j.ocecoaman.2010.11.007

831 Szuster, B.W., Needham, M.D., McClure, B.P., 2011. Scuba Diver Perceptions and Evaluations 832 of Crowding Underwater. Tour. Mar. Environ. 7, 153-165. 833 doi:10.3727/154427311X13195453162778

834 Tseng, Y.P., Kyle, G.T., Shafer, C.S., Graefe, A.R., Bradle, T. a., Schuett, M. a., 2009. Exploring 835 the crowding-satisfaction relationship in recreational boating. Environ. Manage. 43, 496836 507. doi:10.1007/s00267-008-9249-5

837 Vaske, J.J., Donnelly, M.P., 2002. Generalizing the Encounter--Norm--Crowding Relationship. 838 Leis. Sci. 24, 255-269. doi:10.1080/01490400290050718 
839 Vaske, J.J., Shelby, L.B., 2008. Crowding as a Descriptive Indicator and an Evaluative 840 Standard: Results from 30 Years of Research. Leis. Sci. 30, 111-126. 841 doi:10.1080/01490400701881341

842 Vourc'h, 1999. La capacité d'accueil. Une notion essentielle dans les sites naturels. espace $843166,18-22$.

844 Wagar, A., 1964. The carrying capacity of wild lands for recreation. Forest Science 845 Monograph $7 . \quad 31 \quad$ p.

846 http://www.nstrail.com/carrying_capacity/carrying_capacity_of_wild_lands_for_recreation_ 847 wagar_1964.pdf

848 Whitfield, a K., Becker, A., 2014. Impacts of recreational motorboats on fishes: A review. 849 Mar. Pollut. Bull. 83, 24-31. doi:10.1016/j.marpolbul.2014.03.055

850 Widmer, W.M., Underwood, a. J., 2004. Factors affecting traffic and anchoring patterns of 851 recreational boats in Sydney Harbour, Australia. Landsc. Urban Plan. 66, 173-183. 852 doi:10.1016/S0169-2046(03)00099-9

853 Wood, L.J., Fish, L., Laughren, J., Pauly, D., 2008. Assessing progress towards global marine 854 protection targets: shortfalls in information and action. Oryx 42, 340-351. 855 doi:10.1017/S003060530800046X 
Fig. 1. Islets and MPAs considered in this study, with their geographical and managerial characteristics (line 134).

Fig. 2. Proportion of users citing disturbance criteria other than boat and visitor numbers (line 379).

Fig. 3. Projection of disturbance criteria (large black italic font) and coping strategies (large grey font) on the first factorial plan of the MCA. Islets (small dark grey italic font) and boat types (small light grey font) were projected in addition (line 387).

Fig. 4. Boxplots of boat density threshold values obtained from interviews (in white and grey). For each site, a boxplot was plotted per threshold value: (preferred (white), acceptable (light grey) and intolerable (dark grey). Boxplots in black correspond to boat densities per trip observed during weekend days in 2013. The percentages reported underneath boxplots are the proportion of users able to estimate a boat number threshold value. Note that only users considering a high number of boats as a disturbance were asked to estimate these values. The significance of the Wilcoxon test (see § 2.3.4) were reported above each boxplot with ${ }^{*}: \mathrm{p}<0.05 ;{ }^{* *}: \mathrm{p}<0.01$; and ${ }^{* * *}$ : $\mathrm{p}<0.001$ (line 398).

Fig. 5. Boxplots of visitor density threshold values obtained from interviews (in white and grey). For each site, a boxplot was plotted per threshold value: (preferred (white), acceptable (light grey) and intolerable (dark grey). Boxplots in black correspond to boat densities per trip observed during weekend days in 2013. The percentages reported underneath boxplots are the proportion of users able to estimate a boat number threshold value. Note that only users considering a high number of boats as a disturbance were asked to estimate these values. The significance of the Wilcoxon test (see § 2.3.4) were reported above each boxplot with *: $p<0.05 ;{ }^{* *}: p<0.01$; and ${ }^{* * *}: p<0.001$ (line 398). 


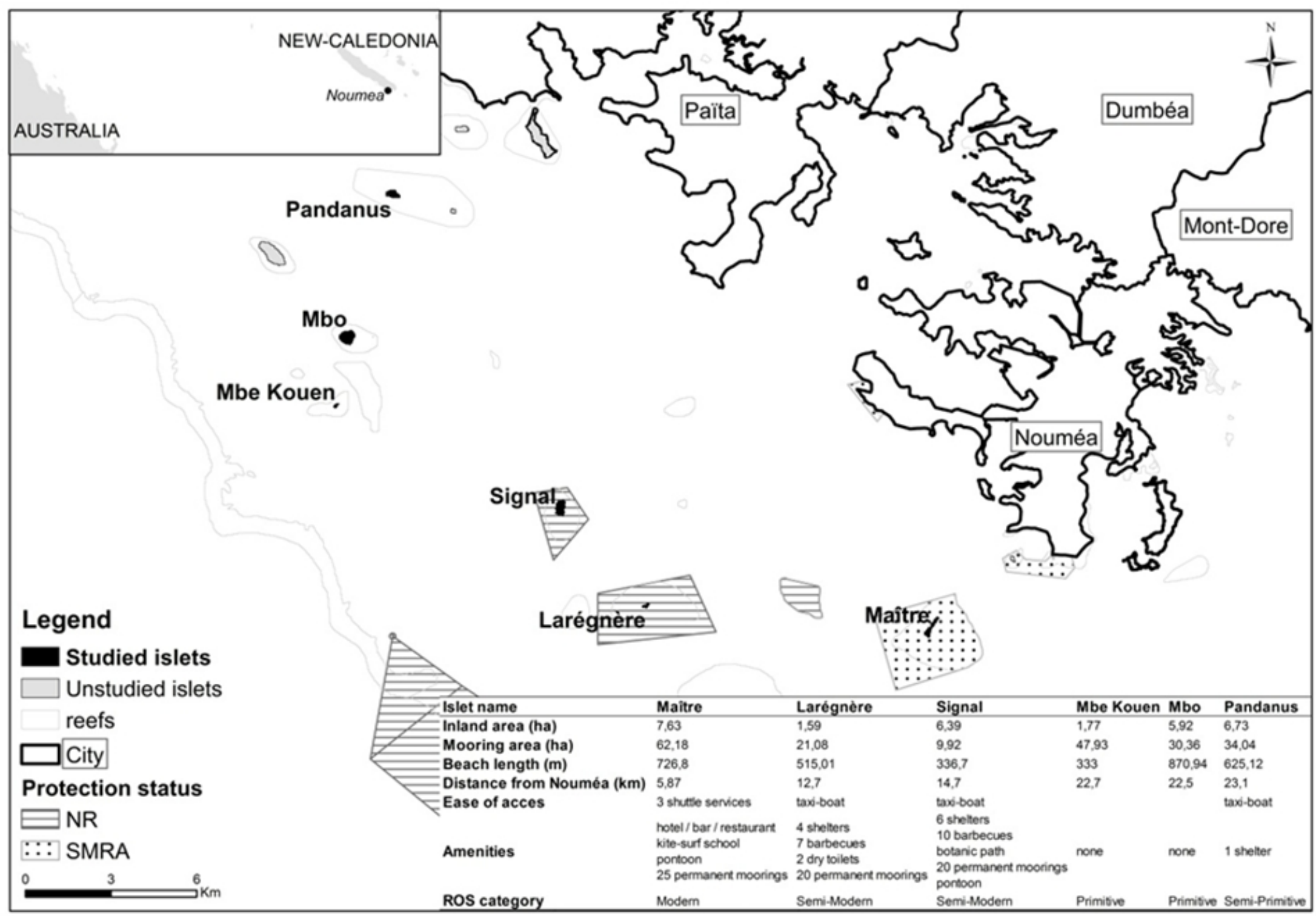




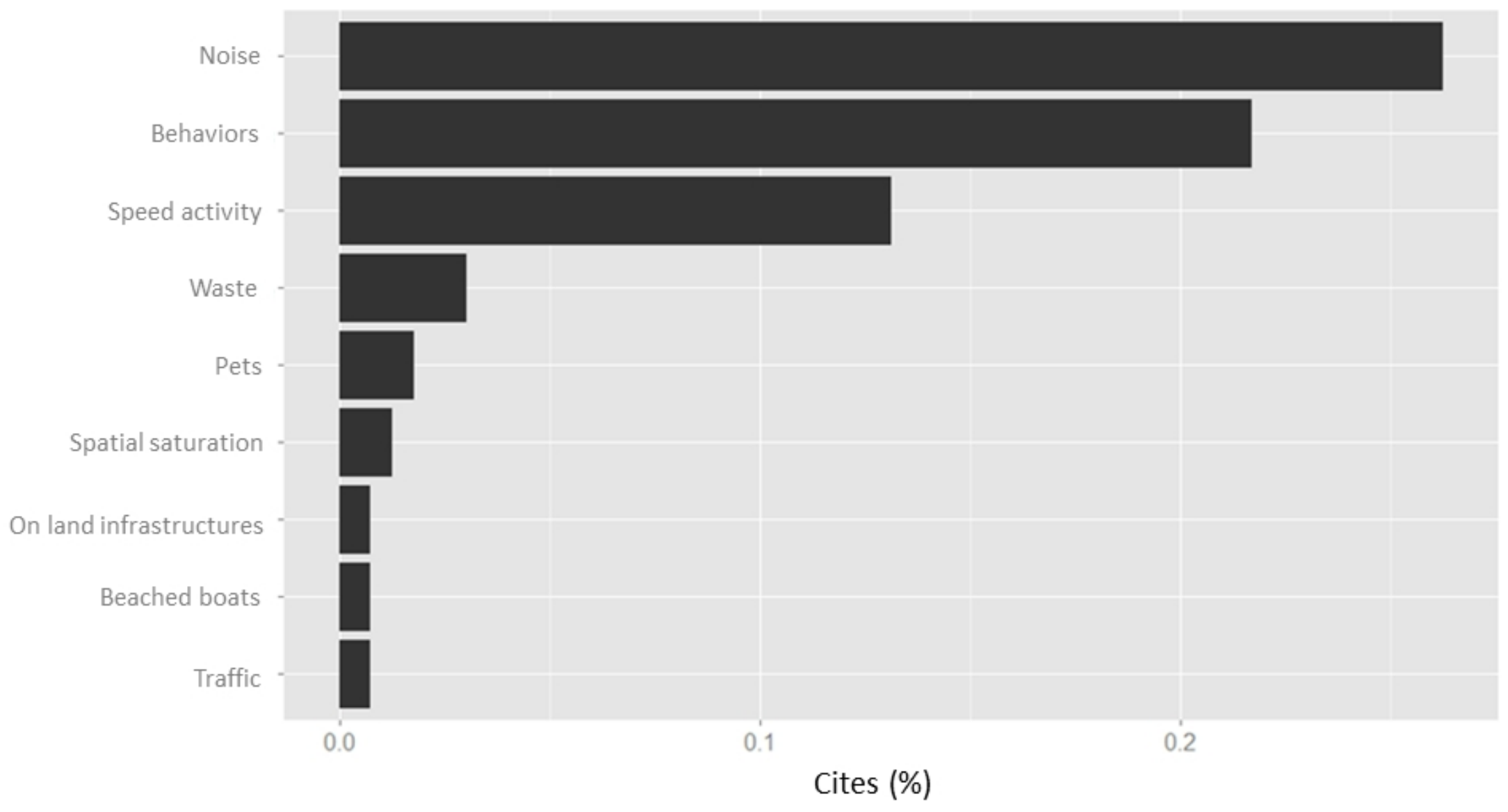




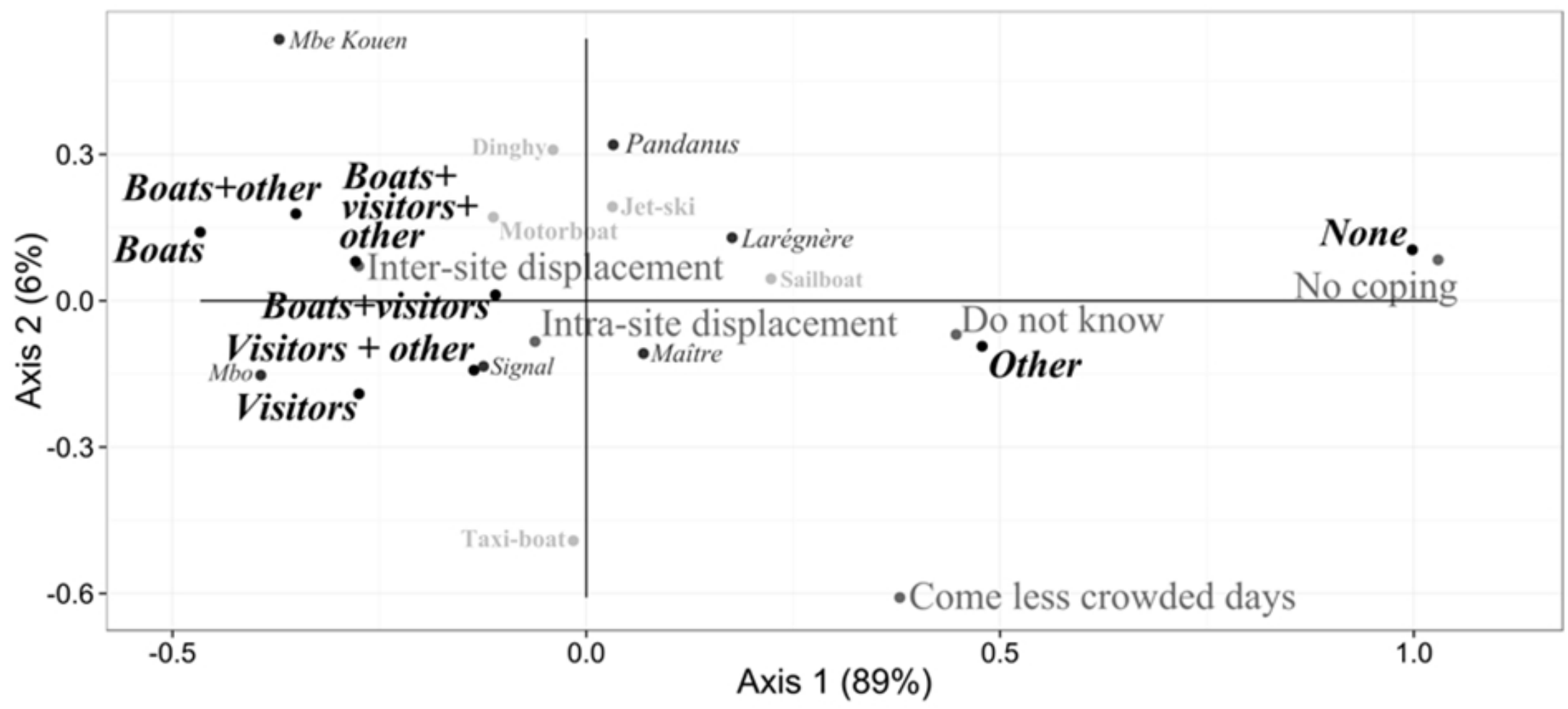




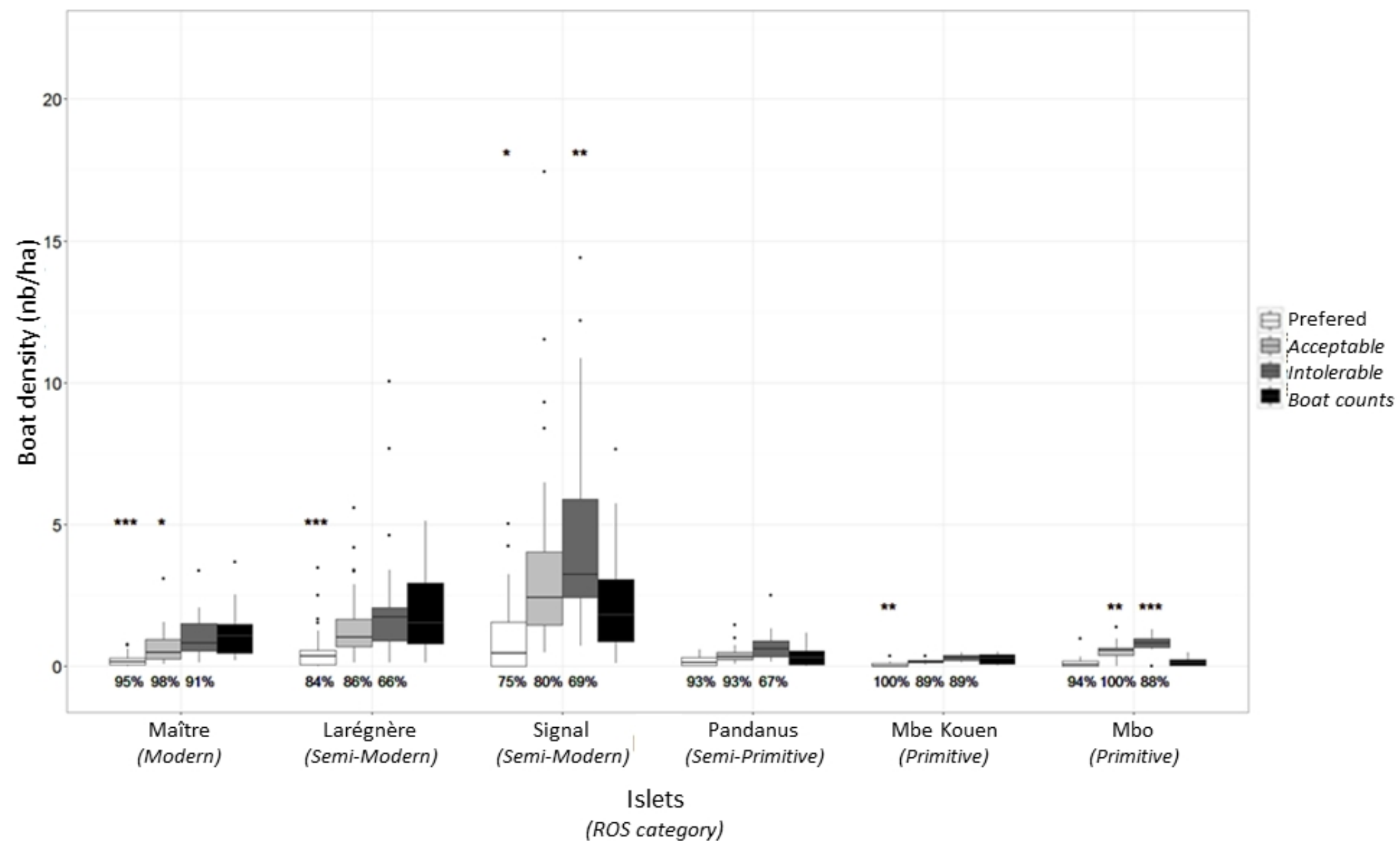




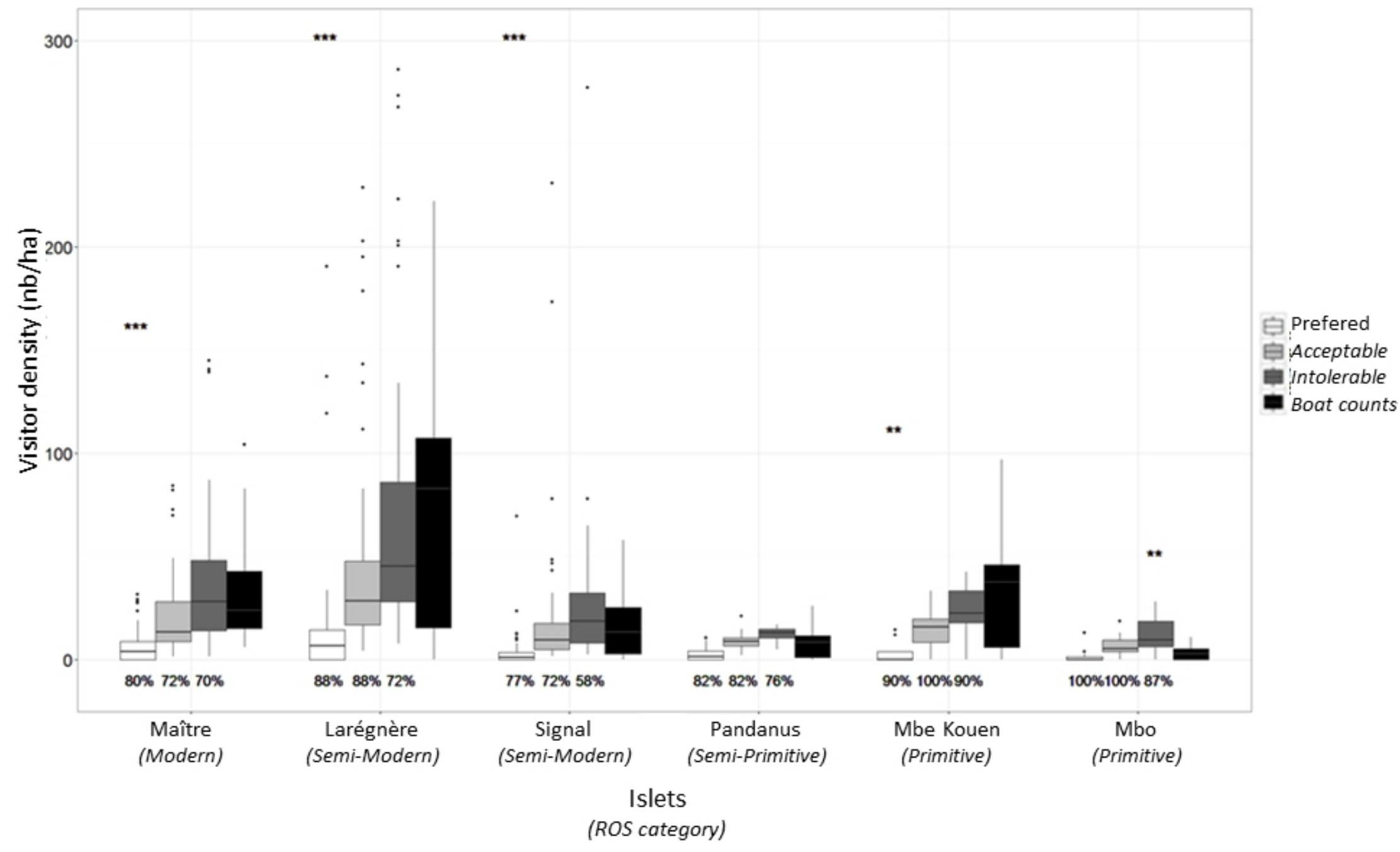


Table 1.Use level observed in 2013 and 2014 per islet. The number of interviews and the mean sampling rate are displayed for each islet in 2014. (line 315)

\begin{tabular}{|c|c|c|c|c|c|c|c|c|c|c|c|c|c|}
\hline \multirow{2}{*}{\multicolumn{2}{|c|}{$\begin{array}{l}\text { Islets } \\
\text { Year }\end{array}$}} & \multicolumn{2}{|c|}{ Maître } & \multicolumn{2}{|c|}{ Larégnère } & \multicolumn{2}{|c|}{ Signal } & \multicolumn{2}{|c|}{ Pandanus } & \multicolumn{2}{|c|}{ Mbe Kouen } & \multicolumn{2}{|c|}{ Mbo } \\
\hline & & 2013 & 2014 & 2013 & 2014 & 2013 & 2014 & 2013 & 2014 & 2013 & 2014 & 2013 & 2014 \\
\hline \multicolumn{2}{|c|}{ Mean number of boats per trip during weekend days } & 69.2 & 42 & 39.2 & 46.2 & 20.9 & 36 & 12.5 & 12.8 & 10 & 6.8 & 7.4 & 7.2 \\
\hline \multicolumn{2}{|c|}{ Mean number of boats per trip during week days } & 7.9 & $\mathrm{x}$ & 4.4 & $x$ & 2.9 & $\mathrm{x}$ & 2.6 & $x$ & 1.5 & $x$ & 1.5 & $x$ \\
\hline \multicolumn{2}{|l|}{ Mean number of visitors per trip } & $x$ & 126.6 & $x$ & 121.4 & $x$ & 167.6 & $x$ & 42.8 & $x$ & 8 & $x$ & 27.4 \\
\hline \multirow[t]{4}{*}{ Proportion of users per boat type (\%) } & sailboat & 11.4 & 21 & 24.5 & 27.8 & 18.6 & 19.3 & 6.6 & 12.5 & 48.3 & 66.7 & 12.1 & 15 \\
\hline & motorboat & 16.8 & 38.5 & 51.8 & 47.6 & 67.7 & 56.1 & 88 & 84.4 & 51.5 & 33.3 & 85.6 & 80 \\
\hline & taxi boat & 66.6 & 37 & 14.5 & 18.7 & 11.9 & 22.8 & 0.8 & 3.1 & 0 & 0 & 1.3 & 5 \\
\hline & jet ski & 5.2 & 3.5 & 9.2 & 5.9 & 1.8 & 1.8 & 4.6 & 0 & 0.2 & 0 & 1 & 0 \\
\hline \multicolumn{2}{|c|}{ Mean trip duration (number of nights on the islet) } & $x$ & 0.5 & $x$ & 0.6 & $x$ & 0.5 & $\mathrm{x}$ & 1.2 & $x$ & 1.2 & $\mathrm{x}$ & 1.3 \\
\hline \multicolumn{2}{|l|}{ Number of interviews } & $x$ & 154 & $x$ & 110 & $x$ & 128 & $x$ & 38 & $x$ & 13 & $x$ & 20 \\
\hline \multicolumn{2}{|l|}{ Mean sampling rate (\%) } & $x$ & 15.6 & $x$ & 15.4 & $x$ & 13.6 & $x$ & 17.6 & $x$ & 32.5 & $x$ & 18 \\
\hline
\end{tabular}


Table 2: Mean estimation error for boat and visitor per level of the factors of interest. For each factor, significant differences between levels were displayed with same letter indices (Kruskal test at $5 \%$ significant level). ${ }^{* * *}: 0.1 \%$ significance level, ${ }^{* *}: 1 \%$ significance level, ${ }^{*}: 5 \%$ significance level based on Kruskal test. (line 335)

\begin{tabular}{|c|c|c|c|}
\hline \multirow{2}{*}{ Factors } & \multirow{2}{*}{ Factor level } & \multicolumn{2}{|c|}{$\begin{array}{l}\text { Mean error estimation } \\
\text { for ... }\end{array}$} \\
\hline & & $\begin{array}{l}\text { Number of } \\
\text { boats }\end{array}$ & $\begin{array}{l}\text { Number of } \\
\text { pers. }\end{array}$ \\
\hline \multirow{6}{*}{ Islet $* * *$} & Maitre & -0.16 & $0.13^{a b}$ \\
\hline & Larégnère & -0.23 & $-0.16^{a}$ \\
\hline & Signal & -0.07 & $-0,29^{b}$ \\
\hline & Pandanus & -0.25 & -0.13 \\
\hline & Mbe kouen & -0.15 & 0.16 \\
\hline & Mbo & -0.23 & -0.23 \\
\hline \multirow{4}{*}{ ROS classes $* * *$} & Modern & -0.16 & $0.13^{a}$ \\
\hline & Semi-modern & -0.23 & $-0.23^{a}$ \\
\hline & Semi-primitive & -0.13 & -0.13 \\
\hline & Primitive & -0.20 & -0.07 \\
\hline \multirow{3}{*}{ On-site location*** } & On the boat & -0.22 & $-0.32^{a}$ \\
\hline & Leeward side & -0.12 & $0.03^{a}$ \\
\hline & Windward side & -0.16 & -0.12 \\
\hline \multirow{2}{*}{$\begin{array}{l}\text { Relative crowding level } \\
* * *\end{array}$} & Relatively high & $-0.27^{a}$ & $-0.05^{a}$ \\
\hline & Relatively low & $-0.20^{a}$ & $0.001^{a}$ \\
\hline \multirow{4}{*}{ City* } & Noumea & -0.17 & $-0.13^{a}$ \\
\hline & $\begin{array}{l}\text { Neighbouring } \\
\text { cities }\end{array}$ & -0.12 & -0.08 \\
\hline & N. Caledonia & -0.09 & -0.13 \\
\hline & $\begin{array}{l}\text { Outside N. } \\
\text { Caledonia }\end{array}$ & -0.28 & $0.31^{a}$ \\
\hline \multirow{6}{*}{$\begin{array}{l}\text { Number of year, } \\
\text { visiting the area * }\end{array}$} & None & $-0.48^{a}$ & 0.32 \\
\hline & Less than 1 & $-0.02^{a}$ & -0.09 \\
\hline & Between 1 and 5 & -0.21 & -0.21 \\
\hline & Between 6 and 10 & -0.17 & -0.20 \\
\hline & $\begin{array}{l}\text { Between } 11 \text { and } \\
20\end{array}$ & -0.12 & -0.10 \\
\hline & More than 20 & -0.16 & 0.01 \\
\hline
\end{tabular}


Table 3: Proportion of user's per crowding perception level as a function of the factors of interest ${ }^{* * *}: 0.1 \%$ significance level, ${ }^{* *}: 1 \%$ significance level, ${ }^{*}: 5 \%$ significance level based on Chi-square test). (line 352)

\begin{tabular}{|c|c|c|c|c|c|}
\hline \multirow{2}{*}{ Factors } & \multirow{2}{*}{ Category } & \multicolumn{4}{|c|}{ Crowding perception } \\
\hline & & Not & Slightly & Crowded & Highly \\
\hline \multirow{6}{*}{ Islet * } & Maître & 73 & 17 & 9 & 1 \\
\hline & Larégnère & 56 & 26 & 14 & 4 \\
\hline & Signal & 42 & 36 & 18 & 4 \\
\hline & Pandanus & 55 & 21 & 21 & 3 \\
\hline & Mbe kouen & 62 & 30 & 8 & 0 \\
\hline & Mbo & 65 & 20 & 15 & 0 \\
\hline \multirow{4}{*}{ ROS classes $* *$} & Modern & 73 & 17 & 9 & 1 \\
\hline & Semi-modern & 49 & 31 & 16 & 4 \\
\hline & Semi-primitive & 55 & 21 & 21 & 3 \\
\hline & Primitive & 64 & 24 & 12 & 0 \\
\hline \multirow{5}{*}{ Boat type * } & Taxi-boat & 58 & 30 & 9 & 2 \\
\hline & Sailboat & 67 & 17 & 16 & 0 \\
\hline & Motorboat & 52 & 28 & 15 & 5 \\
\hline & Jet-ski & 92 & 8 & 0 & 0 \\
\hline & Dinghy & 46 & 29 & 25 & 0 \\
\hline \multirow{3}{*}{ On-site location ${ }^{*}$} & On the boat & 65 & 19 & 16 & 0 \\
\hline & Leeward side & 49 & 29 & 17 & 4 \\
\hline & Windward side & 61 & 27 & 8 & 3 \\
\hline \multirow{2}{*}{$\begin{array}{l}\text { Relative crowding } \\
\text { level } * * *\end{array}$} & Relatively high & 46 & 30 & 20 & 4 \\
\hline & Relatively low & 70 & 21 & 8 & 1 \\
\hline \multirow{3}{*}{$\begin{array}{l}\text { Quietness as an } \\
\text { islet selection } \\
\text { criterion } * * *\end{array}$} & No & 60 & 23 & 14 & 3 \\
\hline & Yes and satisfied & 57 & 40 & 3 & 0 \\
\hline & Yes but not satisfied & 7 & 43 & 43 & 7 \\
\hline \multirow{8}{*}{$\begin{array}{l}\text { Disturbance } \\
\text { related with } \\
\text { crowding depends } \\
\text { on } * * *\end{array}$} & Only number of visitors & 40 & 31 & 23 & 6 \\
\hline & $\begin{array}{l}\text { Number of visitors }+ \\
\text { other }\end{array}$ & 54 & 29 & 13 & 4 \\
\hline & Only number of boats & 57 & 29 & 14 & 0 \\
\hline & Number of boats + other & 75 & 17 & 8 & 0 \\
\hline & $\begin{array}{l}\text { Number of visitors and } \\
\text { boats }\end{array}$ & 43 & 29 & 25 & 3 \\
\hline & $\begin{array}{l}\text { Number of visitors, boats } \\
+ \text { other }\end{array}$ & 46 & 33 & 15 & 5 \\
\hline & $\begin{array}{l}\text { Not number but other } \\
\text { criteria }\end{array}$ & 78 & 17 & 5 & 0 \\
\hline & Never disturbed & 93 & 7 & 0 & 0 \\
\hline
\end{tabular}




\begin{tabular}{llllll}
\hline Age $^{* *}$ & $>50$ & 70 & 18 & 10 & 2 \\
& $40-50$ & 63 & 24 & 13 & 1 \\
$30-40$ & 48 & 25 & 21 & 7 \\
& $<30$ & 50 & 36 & 13 & 1 \\
\hline
\end{tabular}

